\title{
A caspase-dependent cleavage of CDC25A generates an active fragment activating cyclin-dependent kinase 2 during apoptosis
}

\author{
A Mazars ${ }^{1}$, A Fernandez-Vidal ${ }^{1}$, O Mondesert ${ }^{2}$, C Lorenzo ${ }^{2}$, G Prévost ${ }^{3}$, B Ducommun ${ }^{2}$, B Payrastre ${ }^{1}$, C Racaud-Sultan ${ }^{1}$ and \\ S Manenti, ${ }^{*}$
}

The cellular level of the CDC25A phosphatase is tightly regulated during both the normal and genotoxic-perturbed cell cycle. Here, we describe a caspase-dependent cleavage of this protein at residue D223 in non-genotoxic apoptotic conditions. This specific proteolysis generates a catalytically active C-terminal fragment that localizes to the nuclear compartment. Accumulation of this active CDC25A fragment leads to reduced inhibitory phosphorylation of the CDC25A substrate cyclin-dependent kinase 2 (CDK2) on Tyr15. Moreover, CDK2 was found stably associated with this fragment, as well as with an ectopically expressed CDC25A224-525 truncation mutant that mimicks the cleavage product. Ectopic expression of this mutant induced CDK2 Tyr15 dephosphorylation, whereas its catalytically inactive version did not. Finally, this 224-525 mutant initiated apoptosis when transfected into HeLa cells, whereas its catalytic inactive form did not. Altogether, this study demonstrates for the first time that caspase-dependent cleavage of CDC25A is a central step linking CDK2 activation with non-genotoxic apoptotic induction. Cell Death and Differentiation (2009) 16, 208-218; doi:10.1038/cdd.2008.142; published online 17 October 2008

The dual-specificity phosphatase CDC25A is an effector of key molecular steps during $G 1 / S$ and $M$ phases of the cell cycle. The initial function described for CDC25A was to remove the phosphate groups from the Thr14 and Tyr15 residues of cyclin-dependent kinase 2 (CDK2), allowing complete activation of this kinase and further progression of cells to $S$ phase. ${ }^{1,2}$ A similar function of CDC25A was also described during mitosis, participating in the activation of the Cdc2 kinase. ${ }^{3}$ CDC25A is one of the three members of the CDC25 phosphatase family, which all directly activate CDKs throughout the cell cycle (for a recent review, see Boutros et al. ${ }^{4}$ ). The specificity of CDC25A, over the B and C isoforms, is its essential function as a G1 phase regulator, and therefore, its regulation by extracellular signaling events. In addition, regulation through ubiquitin-dependent proteasomal degradation of the protein has been extensively described during the last few years, and participates in the G1/S cell cycle arrest and checkpoint (for a review, see Busino et al. ${ }^{5}$ ). The cellular level of CDC25A is also dependent on mitogenic extracellular signals such as growth factors ${ }^{6}$ and IL-7. ${ }^{7}$ We also recently described that adhesion of acute myeloid leukemia (AML) cells to an extracellular matrix upregulates the level of this protein, leading to increased proliferation. ${ }^{8}$

Less characterized than its role during the cell cycle are the potential functions of CDC25A during the apoptotic process. A pro-apoptotic role has been attributed to this phosphatase downstream of Myc-induced apoptosis, ${ }^{9}$ with CDC25A being a direct transcriptional target of Myc in this context. Conversely, an antiapoptotic function has also been ascribed to the protein in response to serum starvation-induced cell death. ${ }^{10}$ Interestingly, a direct interaction of CDC25A with the apoptosis signal regulated kinase-1 (ASK-1) was reported, leading to the inhibition of this kinase and of the subsequent apoptotic process. ${ }^{11}$ Intriguingly, this effect was shown to be independent of the CDC25A catalytic activity.

In the present study, we investigated the status of the CDC25A protein during apoptosis in leukemic cells. We demonstrate that apoptotic induction in these cells induces a caspase-dependent cleavage of CDC25A, generating a nuclear active C-terminal fragment involved in CDK2 activation. Our data also suggest that this fragment could be involved in the apoptotic process itself.

\section{Results}

CDC25A is cleaved in response to various apoptotic stimuli. Leukemic cells are highly sensitive to proteasome inhibitors, which are potent apoptotic inducers in these cell types. The U937 AML cell line was treated for 5 or $15 \mathrm{~h}$ with the proteasome inhibitor MG-132. As shown in Figure 1a (left), after $5 \mathrm{~h}$ of treatment with this drug, cells did not significantly enter apoptosis, as deduced by the absence of cleavage of the poly (ADP-ribose) polymerase (PARP)

${ }^{1}$ Département 'Oncogenèse et Signalisation dans les cellules Hématopoḯtiques', INSERM U563-IFR30, Centre de Physiopathologie Toulouse-Purpan, CHU Purpan, 31024 Toulouse Cedex 3, France; ' ${ }^{2}$ aboratoire de Biologie Cellulaire et Moléculaire du Contrôle de la Prolifération, CNRS UMR 5088-IFR 109, Université Paul Sabatier, Toulouse, France and ${ }^{3}$ IPSEN, Research Laboratory, Institut Henri Beaufour, Les Ulis Cedex, France

${ }^{*}$ Corresponding author: S Manenti, Département 'Oncogenèse et Signalisation dans les Cellules Hématopoïétiques', INSERM U563-IFR 30, Bât B, CHU Purpan, BP3028, 31024 Toulouse Cedex 3, France. Tel: + 335627445 24; Fax: + 335627445 58; E-mail: stephane.manenti@inserm.fr

Keywords: CDC25A; apoptosis; cleavage; caspase; cyclin-dependent kinase

Abbreviations: AML, acute myeloid leukemia; CDK2, cyclin-dependent kinase 2; FACS, fluorescence-activated cell sorting; FDP, fluorescein diphosphate; NES, nuclear export sequence; NLS, nuclear localization sequence; PARP, poly (ADP-ribose) polymerase; STS, staurosporin; TNF- $\alpha$, tumor necrosis factor alpha Received 06.11.07; revised 01.7.08; accepted 14.8.08; Edited by B Zhivotovsky; published online 17.10 .08 

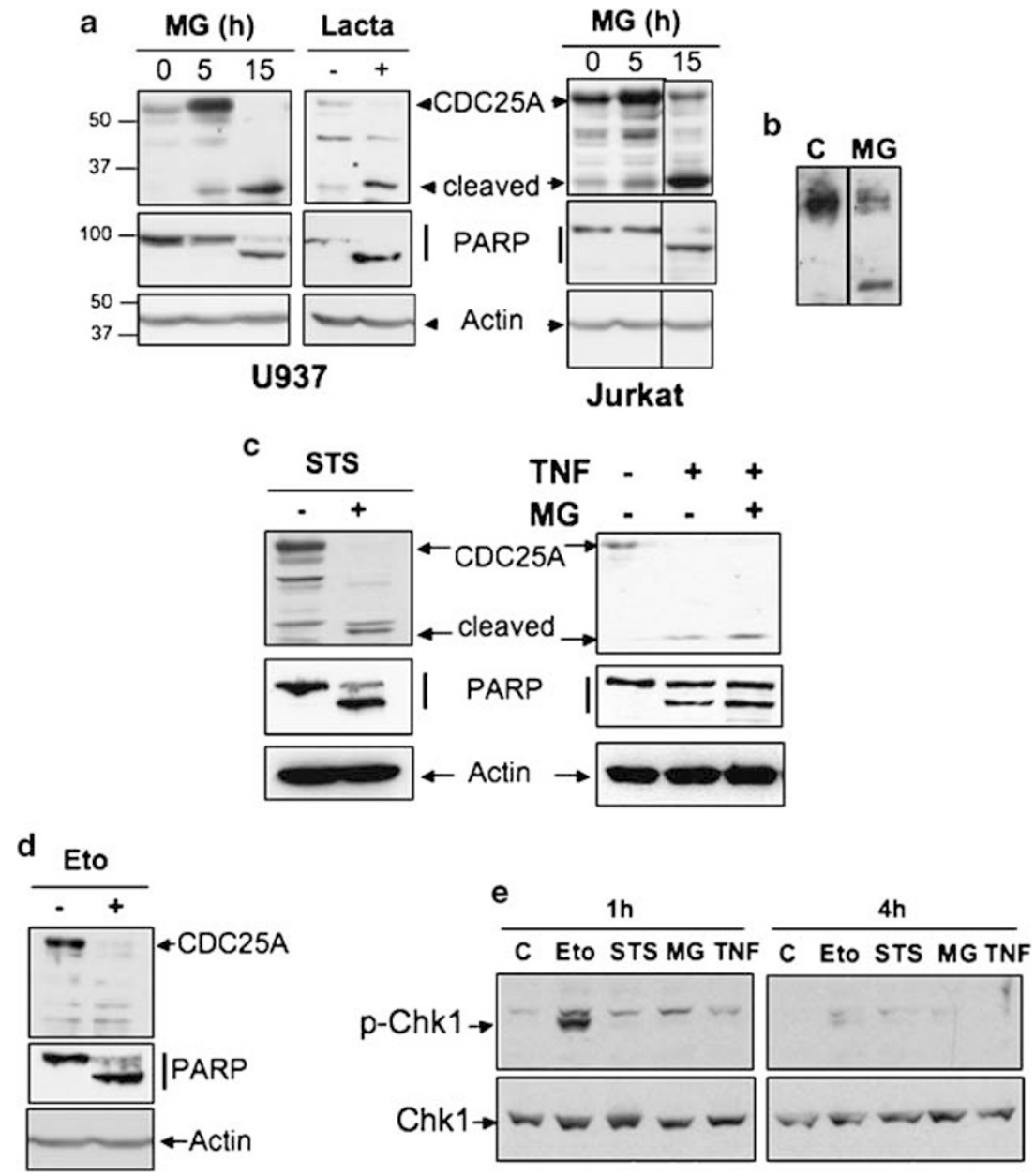

Figure 1 Downregulation and cleavage of cdc25A during apoptosis. (a) Left: U937 cells were treated for 5 or $15 \mathrm{~h}$ with $5 \mu \mathrm{M}$ of the proteasome inhibitor MG-132 (MG) or $15 \mathrm{~h}$ with $5 \mu \mathrm{M}$ lactacystin (lacta). Right: Jurkat cells were treated similarly to U937 cells. Western blot analysis of the corresponding crude fractions was then performed with an antibody against cdc25A. Apoptosis induction was followed by western blot analysis of PARP cleavage with an antibody recognizing full-length and cleaved form of PARP. Control of protein loading was achieved with an antibody against actin. (b) U937 cells were treated for $16 \mathrm{~h}$ with MG-132. Immunoprecipitation of CDC25A was performed from control (C) and treated (MG) cells with the monoclonal antibody (F-6; Santa Cruz) and the immunoprecipitate was analyzed by western blot with a polyclonal antibody (M-191; Santa Cruz). (c) Left: U937 cells were treated for $4 \mathrm{~h}$ with staurosporine (STS: $1 \mu \mathrm{M}$ ) or TNF- $\alpha$ (TNF: $20 \mathrm{ng} / \mathrm{ml}$ ) to induce apoptosis. CDC25A, PARP cleavage and protein loading were analyzed by western blot as described in (a). Right: U937 cells were treated for $4 \mathrm{~h}$ with TNF- $\alpha$ (TNF: $20 \mathrm{ng} / \mathrm{ml}$ ) to induce apoptosis and analyzed as above. Alternatively, cells were incubated with $5 \mu \mathrm{M}$ MG-132 for the last $2 \mathrm{~h}$ of TNF treatment. (d) Experiment performed as in (c and d), but with the DNA topoisomerase II inhibitor etoposide $(50 \mu \mathrm{M})$ for $4 \mathrm{~h}$. (e) Cells were treated for 1 (left panel) or 4 (right panel) hours with either etoposide (Eto), staurosporine (STS), MG-132 (MG) or TNF- $\alpha$ (TNF). C: control cells. Chk1 activation was detected in the corresponding fractions with an antibody against the phosphorylated Ser345 residue (p-Chk1). Western blot against the Chk1 protein was used as a control

protein. In these conditions, accumulation of the CDC25A protein was observed. When cells were treated for $15 \mathrm{~h}$ with MG-132, a robust apoptosis occurred as judged by the cleavage of PARP. In these cells, the CDC25A protein completely disappeared, whereas a 33-kDa peptide was detected by western blot. Similar effects were observed with Jurkat cells (Figure 1a, right). The more specific proteasome inhibitor lactacystin had the same effect (Figure 1a, left). As we used an antibody directed against the $C$ terminus of CDC25A, these data suggest that during the apoptosis process, a C-terminal cleavage fragment of CDC25A is generated. To confirm the identity of this fragment, we performed immunoprecipitation on apoptotic cells with a monoclonal antibody raised against the $C$ terminus of CDC25A (F-6; Santa Cruz), and western blot analysis with an anti-CDC25A polyclonal antibody (M-191; Santa Cruz), to show that this 33-kDa band was indeed due to CDC25A processing (Figure 1b). We then asked whether other wellknown apoptosis inducers would generate this peptide. As shown in Figure 1c, treatment of U937 cells with apoptotic concentrations of staurosporine (STS) (left) or tumor necrosis factor alpha (TNF- $\alpha)$ (right) also led to concomitant downregulation of CDC25A and accumulation of a $33-\mathrm{kDa}$ product recognized by the anti-CDC25A antibody. As the 33-kDa peptide appeared more abundant following MG-132 treatment than with the other apoptosis inducers, we reasoned that production of this cleavage fragment could be dependent of the proteasome activity. To test this hypothesis, cells were treated with TNF- $\alpha$ to induce apoptosis, and with MG-132 during the last $2 \mathrm{~h}$ of incubation. 
This effectively induced an accumulation of the 33-kDa fragment, suggesting that proteasome activity influences the cleavage intensity of CDC25A (Figure 1c, right).

Proteasome-dependent downregulation of CDC25A in response to genotoxic stress has been extensively documented. Therefore, we tested the effect of the topoisomerase II inhibitor etoposide on these cells. As shown in Figure 1d, this drug induced complete CDC25A downregulation, but did not generate any detectable cleavage product, although apoptosis was effectively induced in these conditions. Similar results were observed when cells were treated with daunorubicin, another genotoxic agent currently used in AML therapies (not shown). This suggests that the major CDC25A downregulation pathway is different in genotoxic and nongenotoxic apoptotic conditions.

Because proteasome-dependent degradation of CDC25A is largely dependent on phosphorylation by Chk1, we followed Chk1 activation through phosphorylation of its residue Ser345. As expected, robust and transient Chk1 activation was detected on treatment with etoposide, whereas no activation was observed with the other apoptotic inducers MG-132, STS and TNF- $\alpha$ (Figure 1e). Altogether, these data suggest that non-genotoxic apoptosis stimuli induce CDC25A cleavage, generating a $33-\mathrm{kDa}$ C-terminal fragment of the protein in a Chk1-independent manner. This product will be referred to as p33-tCDC25A here onwards.

Cellular cleavage of CDC25A is a caspase-dependent process. We then investigated the involvement of the caspase family of proteases in this cleavage of CDC25A. Cells induced for apoptosis with STS were preincubated for $30 \mathrm{~min}$ with the caspase inhibitors Z-VAD-FMK or Z-DEVDFMK. As shown in Figure 2a, both inhibitors suppressed CDC25A cleavage, suggesting caspase involvement in this process. A similar effect was observed with the Z-IETD-FMK inhibitor (not shown). To confirm these data, we used U937 cells stably expressing the baculovirus caspase-inhibitory protein p35. ${ }^{12,13}$ When apoptosis was induced in these cells, CDC25A cleavage was significantly reduced by comparison with control cells (Figure 2b). Altogether, these data demonstrate that caspases are involved in the cleavage of cdc25A during apoptosis.

CDC25A is cleaved at residue D223 in vitro and in cellulo. We then performed experiments aimed at the identification of the cleavage site(s) in CDC25A. We first tested the cleavage of CDC25A by caspase-3 in vitro. In vitro translated wild-type CDC25A was incubated with recombinant caspase-3 (Figure 3b). Wild-type CDC25A was cleaved by caspase-3, giving rise to a $33-\mathrm{kDa}$ fragment co-migrating with the 224-525 truncation mutant mimicking the fragment generated by cleavage at residue 223 .

We identified three consensus sites for caspase cleavage in the sequence, lying at positions 213DEDD216, 220DLLD223, and 333DPRD336, respectively (Figure 3a). Cleavage occurring at residues D216 and D223 would theoretically generate a C-terminal fragment of CDC25A with an apparent MW of $33 \mathrm{kDa}$. In consequence, we generated the point mutants of these sites (D216A and D223A), as well as the double D216A/ D223A mutant. When the in vitro translated D223A mutant
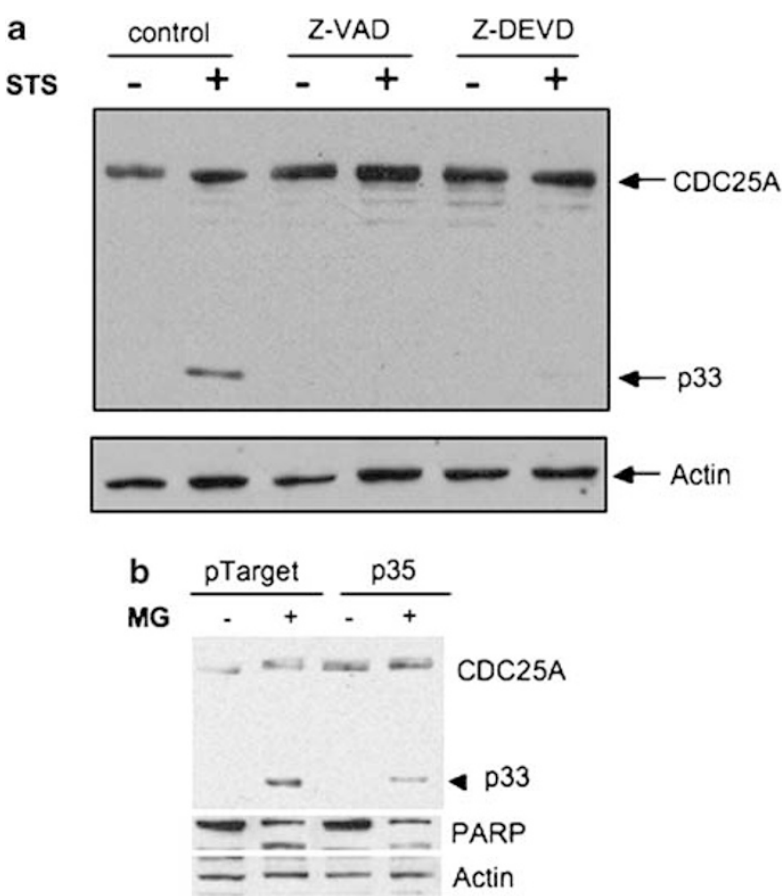

Figure 2 Cellular cleavage of CDC25A by caspases. (a) U937 cells were treated with staurosporine (STS) for $5 \mathrm{~h}$ in the presence or absence of the caspase inhibitors Z-VAD-FMK (Z-VAD; $10 \mu \mathrm{M})$ and Z-DEVD-FMK (Z-DEVD; $5 \mu \mathrm{M})$. CDC25A and actin were detected by western blot in the corresponding fractions as described in Figure 1. (b) U937 cells stably expressing the baculovirus caspase inhibitor p35 (p35) or the empty vector (pTarget) were treated for $15 \mathrm{~h}$ with MG-132 (MG: $2.5 \mu \mathrm{M}$ ). CDC25A and PARP were then detected by western blot in the corresponding fractions. Control of protein loading was achieved by using an antibody against actin

was incubated in the presence of recombinant caspase-3, the cleavage was completely impaired (Figure 3b). By contrast, the D216A mutant of the protein was still processed by this caspase. Similarly to D223A, the double D216A/D223A mutant was not cleaved. We then transfected human cervical carcinoma (HeLa) cells with these different CDC25A isoforms (Figure 3c). When WT CDC25A was transfected, the full-size protein was detected, as well as the $33-k D a$ fragment. We interpreted these results by the fact that ectopic overexpression of the protein induces its cleavage, or that the transfection protocol used for these experiments induced some apoptosis. When the D223A or D216A/D223A mutants where used, the $33-\mathrm{kDa}$ fragment could not be detected by western blot, confirming the results obtained in vitro. As controls, we used the 224-525 truncation mutant, which mimicks the C-terminal peptide generated by the cleavage and perfectly co-migrates with this fragment. A proteasome degradation-resistant mutant (S82A/S88A) was cleaved similarly to the wild-type protein in these conditions. We then verified that the ectopic protein could be cleaved during STS-induced apoptosis. HeLa cells were transfected with WT CDC25A, and further treated with STS to induce apoptosis (Figure $3 d$ ). In these conditions, production of the ectopic 33-kDa fragment was increased, by comparison with untreated cells. Neither full-length nor truncated endogenous CDC25A could be detected in this cell type, probably due to low expression level of the protein. Furthermore, the D223A mutant was cleaved neither by the 

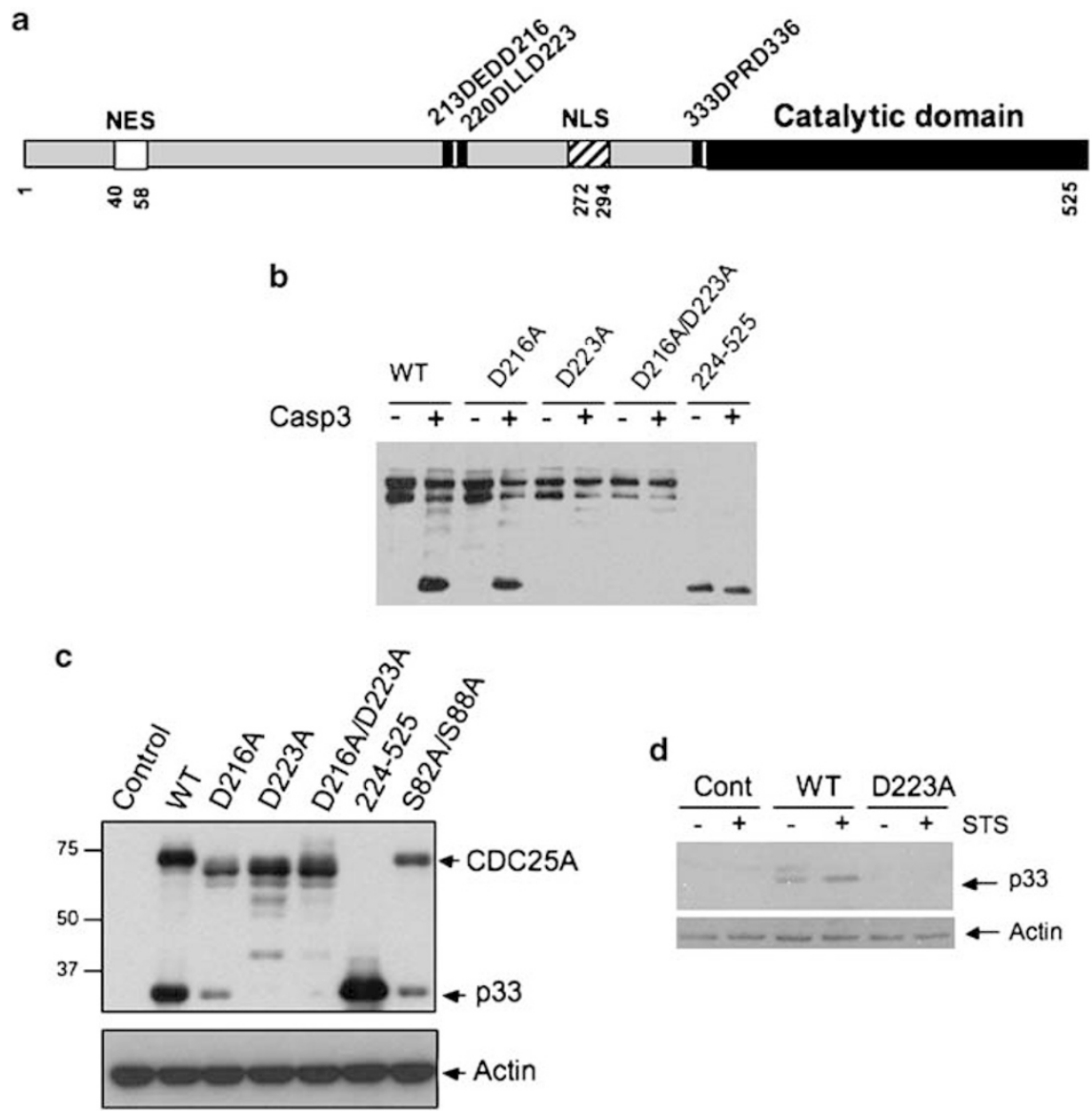

d

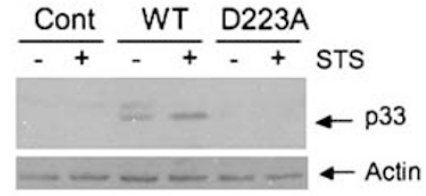

Figure 3 CDC25A is cleaved at residue D223. (a) Schematic presentation of the CDC25A structure. The published nuclear export sequence (NES), nuclear localization sequence (NLS) and catalytic domains are indicated. Three consensus sites for cleavage by caspase are included. (b) In vitro translated WT CDC25A as well as D216A, D223A, D216A/D223A and 224/525 mutants were translated in vitro and subjected to a cleavage assay with recombinant caspase-3 as described in Materials and Methods. CDC25A and its cleavage product (p33) were detected by western blot. (c) HeLa cells were transfected with cDNAs of the indicated forms of CDC25A and the corresponding fractions were analyzed by western blot for the presence of the p33-tCDC25A fragment (p33). D216A and D223A are point mutants of the potential cleavage sites by caspases, D216A/D223A is the corresponding double mutant, 224-525 is a truncation mutant mimicking the C-terminal fragment generated by cleavage at residue 223, and $\mathrm{S} 82 \mathrm{~A} / \mathrm{S} 88 \mathrm{~A}$ is a mutant resistant to proteasome degradation. (d) Same experiment as in (c), but cells were further treated with staurosporine to induce apoptosis. The transfection was performed with the wild-type CDC25A (WT) and the D223A mutant

transfection itself nor by STS treatment. Altogether, these data demonstrate that caspase(s) cleave CDC25A at residue D223 and generate a C-terminal stable fragment. They also indicate that CDC25A cleavage is not specific of hematopoietic cells as it also occurs in HeLa cells.

p33-tCDC25A carries phosphatase activity. We then investigated the enzymatic activity of p33-tCDC25A. First, the phosphatase activity was tested using in vitro translated wild-type and 224-525 CDC25A mutant. This mutant mimicks the endogenous p33-tCDC25A generated during apoptosis. These two proteins were translated in vitro, immunoprecipitated, and tested for their phosphatase activity with fluorescein diphosphate (FDP) as a synthetic substrate. The results shown in Figure $4 a$ indicate that the 224-525 mutant maintains catalytic activity by comparison with the wild-type protein. To investigate the cellular activity of p33-tCDC25A, cells were treated for 15h with MG-132. Immunoprecipitation of CDC25A and/or p33-tCDC25A was then performed, and the immunoprecipitated phosphatase activity was measured by comparison with untreated cells. As shown in Figure $4 \mathrm{~b}$, similar phosphatase activity was detected in the immunoprecipitates from the control fractions and from those induced for apoptosis with MG-132, suggesting that the cleavage product of CDC25A is indeed catalytically active. The catalytic activity of $75 \mathrm{ng}$ of recombinant maltose-binding protein (MBP)-CDC25B3 was measured as a positive control in these experiments, and its inhibition by the CDC25 inhibitor BN82685 is shown. Western blot analysis of these fractions confirmed the presence of the full-length protein in control cells, its absence in the apoptotic cells, and the presence in these cells of the p33-tCDC25A peptide (Figure 4b, upper panel). To get insight into the relative specific activities of the fulllength and the truncated forms of CDC25A, we quantified the relative amount of each isoform by densitometric analysis of the western blots. The measured catalytic activities were then normalized to these values, allowing a comparison of the specific activities carried out by the full-length and the truncated isoforms (Figure 4c). The data presented in 


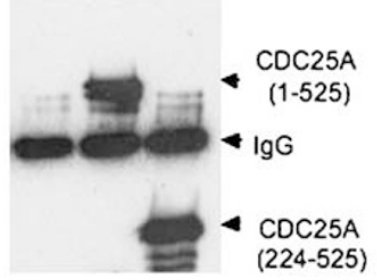

b
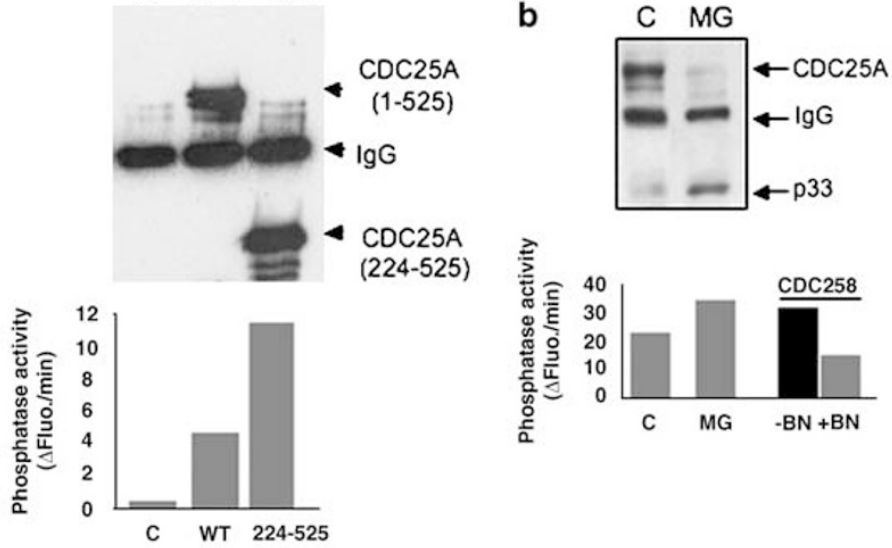

224-525)
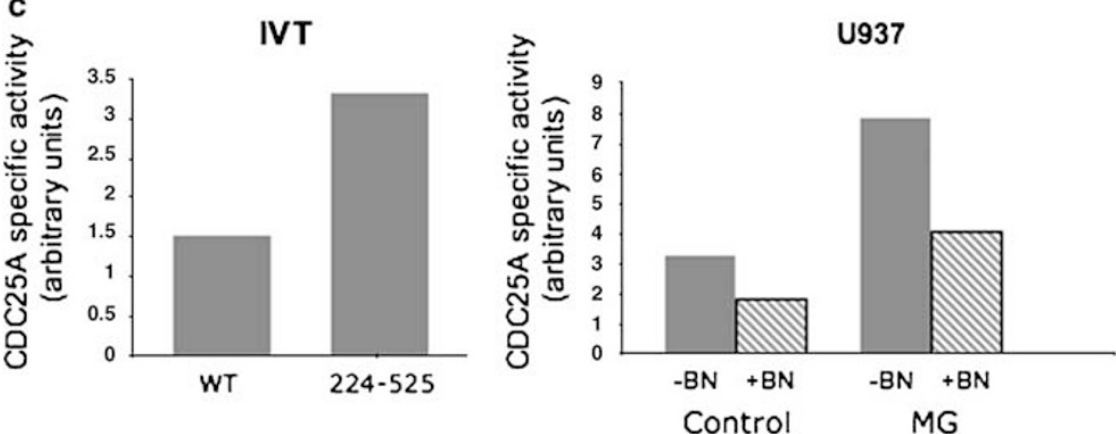

Figure 4 p33-tCDC25A contains phosphatase activity. (a) WT and truncated 224-525 CDC25A were produced in vitro, and immunoprecipitated. Western blot analysis of immunoprecipitated CDC25A isoforms was then performed (upper panel). Phosphatase activity was measured on the immunoprecipitates as described in Materials and Methods, with FDP (fluorescein diphosphate) as a substrate. The activities (lower panel) were expressed in $\Delta$ Fluo./min. These results are representative of three independent experiments. (b) U937 cells were incubated with DMSO (C) or with $5 \mu \mathrm{M}$ MG-132 (MG) for $15 \mathrm{~h}$, lysed, and the extracts were submitted to immunoprecipitation and phosphatase activity as described in (a). As in (a), western blotting analysis of the immunoprecipitates was performed (upper panel). As a comparison, the activity of $75 \mathrm{ng}$ of recombinant MBP-CDC25B was measured in the presence $(+B N)$ or absence $(-B N)$ of the CDC25 inhibitor $(B N$ : $50 \mathrm{nM})$. These results are representative of two independent experiments. (c) Densitometric analysis of the western blots in (a and $\mathbf{b})$ was performed, and the phosphatase activities measured in each fraction were normalized with these densitometric values. The corresponding relative specific activities are shown (arbitrary units). In the case of the fractions immunoprecipitated from U937 cells (right panel), the experiment was performed in the presence $(+B N)$ or absence $(-B N)$ of the CDC25 inhibitor BN82685 $(50 \mathrm{nM})$

Figure $4 \mathrm{C}$ show that the truncated form of CDC25A is 2-2.5 $\times$ more active than the full-length version of the protein, both for the in vitro translated protein (left panel) and for the endogenous cellular CDC25A immunoprecipitated from $U 937$ cells (right panel). The in vitro phosphatase assay from U937-immunoprecipitated CDC25A was performed in the presence of the CDC25 inhibitor BN82685, and the inhibition observed in the presence of this compound confirmed that this enzymatic activity was actually due to a CDC25 phosphatase.

Nuclear localization of p33-tCDC25A. Both nuclear localization sequence (NLS) and nuclear export sequence (NES) have been identified in the CDC25A structure. ${ }^{14}$ The $\mathrm{C}$-terminal fragment of the protein corresponding to residues 224 to 525 contains the catalytic domain and the NLS, but not the NES domain (see Figure 3). In consequence, we tested the cellular localization of the p33-tCDC25A peptide. Cells induced for apoptosis with lactacystin were fractionated into cytoplasmic and nuclear fractions, and p33-tCDC25A was detected by western blot. As shown in Figure $5 \mathrm{a}$, this peptide was concentrated in the nuclear fraction in these experiments. Full-length CDC25A was also detected in the nuclear fraction in control cells in the same conditions. To further define the relative localization of CDC25A N- and C-terminal fragments during the apoptotic process, we used a chimeric protein mCFP-wtCDC25A-YFP corresponding to wtCDC25A in fusion with the mCeruleanprotein at its $\mathrm{N}$ terminus and the citrine protein at its $\mathrm{C}$ terminus. HeLa cells were transfected with this construct, induced for apoptosis with STS, and ectopic CDC25A was followed by fluorescence video-microscopy on living cells. Figure $5 b$ gives the color merged images with the mCFP in green and YFP in red corresponding respectively to $\mathrm{N}$ - and $\mathrm{C}$ termini of the chimeric protein. A major nuclear colocalization (yellow color) of $\mathrm{N}$ - and $\mathrm{C}$ termini was detected in control untreated cells (Figure $5 \mathrm{~b}$ ) that was maintained during more than $3 \mathrm{~h}$. When transfected cells were treated with STS, the C- (in red) and the $\mathrm{N}$ termini (in green) were quickly separated from each other, giving rise to a stable red labeling of the nuclei, and the disappearance of the green labeling in most cases, and its transient maintenance in a non-nuclear, probably 
a

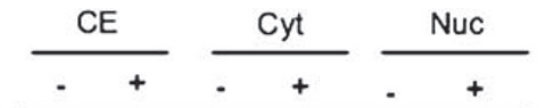

Lacta
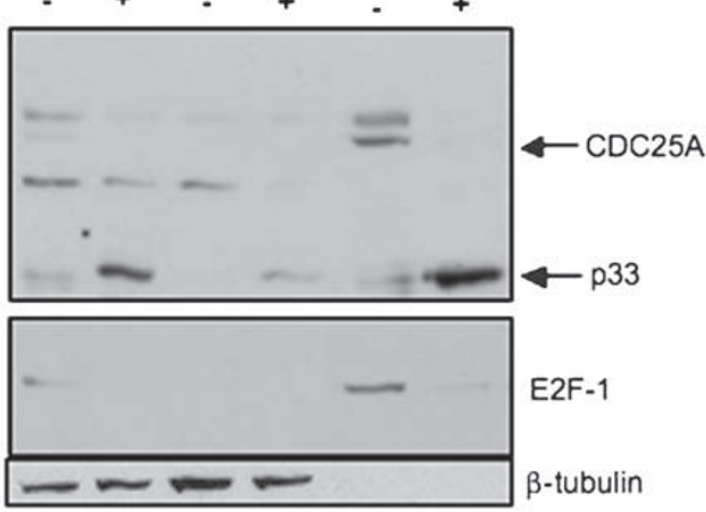

E2F-1

$\beta$-tubulin

\section{b Control}
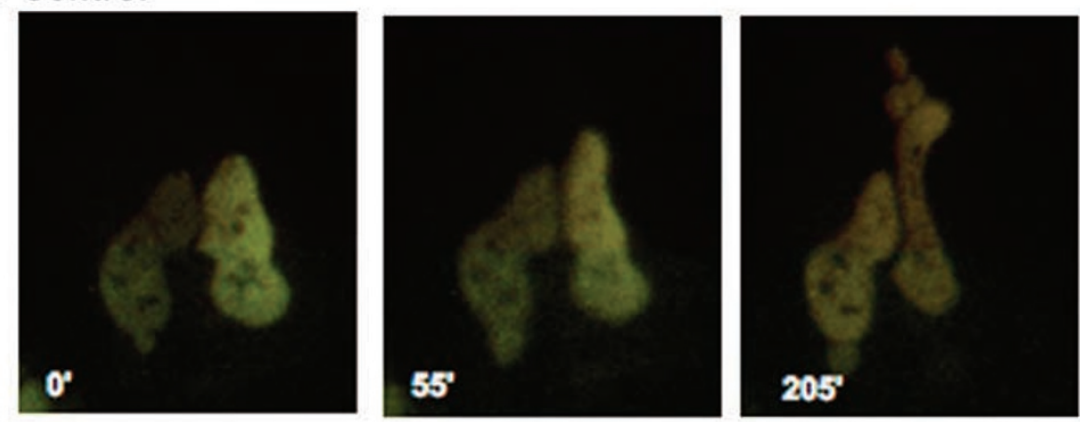

\section{STS}
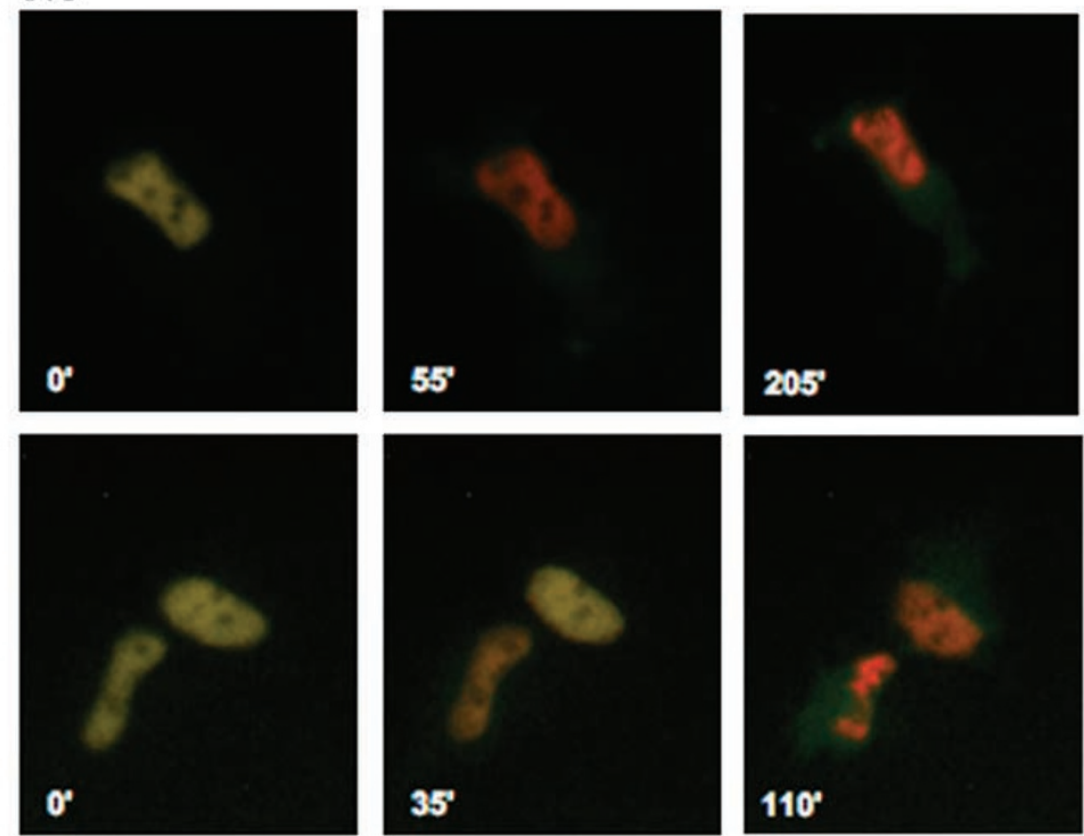

Figure 5 Nuclear localization of p33-tCDC25A. (a) Crude (CE), cytosolic (Cyt), and nuclear (Nuc) extracts were prepared from U937 cells in the presence or absence of lactacystin for $15 \mathrm{~h}$. Protein samples were prepared as described in Materials and Methods and blotted with antibodies against CDC25A. E2F-1 was used as a nuclear marker and $\beta$-tubulin as a cytoplasmic one. (b) HeLa cells were transfected with the mCFP-CDC25A-YFP construct for $24 \mathrm{~h}$. Cells were treated with or without staurosporine ( $\mu \mathrm{M})$ and then followed by videomicroscopy as described in Materials and Methods. Overlay images depicting changes in yellow/cyan localization during CDC25A cleavage. These images are extracted from a sequence 
cytoplasmic, compartment. These data confirm the cleavage of CDC25A on apoptosis induction, and the nuclear anchoring of the corresponding $\mathrm{C}$-terminal fragment. When we used an N-terminal-specific antibody against CDC25A, we could not detect the endogenous $\mathrm{N}$-terminal half of the protein in any of our apoptotic conditions (not shown), suggesting that this fragment is rapidly degraded in the cytoplasmic compartment. In conclusion, p33-tCDC25A is a nuclear and catalytically active peptide that may have some remaining function during apoptosis.

CDK2 is a target of p33-tCDC25A in apoptotic cells. As the major function of cdc25A described so far is to remove the phosphate group on the CDC2 and CDK2 Tyr15 residue, we tested the Tyr15 phosphorylation status of these two CDKs under apoptotic conditions. Cells were treated with MG-132 for 5 or $15 \mathrm{~h}$ as described before. Immunoprecipitation of CDC2 and CDK2 was then performed, and the resulting immunoprecipitates were analyzed by western blotting with an antibody recognizing Tyr15 phosphorylated CDK1 or CDK2. As shown in Figure 6a, CDC2 Tyr15 phosphorylation was not significantly different in the 5- and $15 \mathrm{~h}$-treated fractions, although the general cellular level of the protein was slightly increased in these conditions. By contrast, CDK2 Tyr15 phosphorylation was reduced in apoptotic cells treated with MG-132 for $15 \mathrm{~h}$. To confirm these data, we performed the reverse experiment. Immunoprecipitation was performed with the anti-phosphoTyr15 antibody, followed by western blot detection of CDK2 or CDC2. As shown in Figure 6b, less CDK2 was immunoprecipitated from apoptotic (MG-132 15h or STS $4 \mathrm{~h}$ ) than from control cells, confirming the results shown in Figure 6a. By contrast, and in good agreement with the results in Figure 6a, the amount of immunoprecipitated Tyr15 CDC2 was increased in the apoptotic cells, probably reflecting the increase of this protein level in these cells.
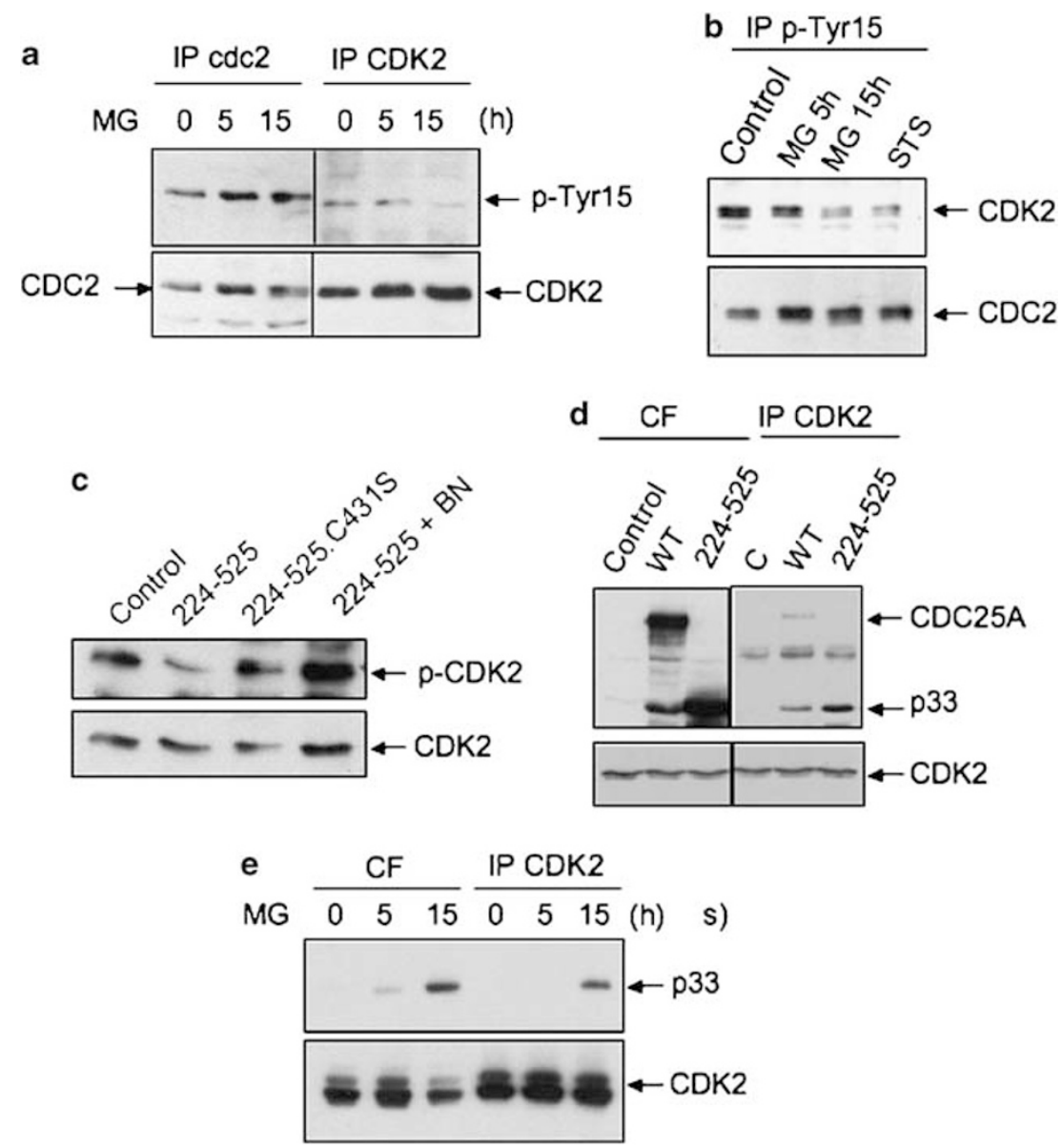

Figure 6 Tyr15 phosphorylation of CDC2 and CDK2 in apoptotic cells. (a) U937 cells were treated for $15 \mathrm{~h}$ with MG-132 (MG) to induce apoptosis. Immunoprecipitation of CDC2 or CDK2 was then performed, and Tyr15 phosphorylation of the immunoprecipitated proteins was analyzed by western blot with an antibody raised against phosphoTyr15 (p-Tyr15). As a control, CDC2 and CDK2 were also detected in the immunoprecipitates by western blot. (b) Cells were processed with MG-132 (MG: $5 \mu \mathrm{M})$ as in (a), or with staurosporine (STS: $1 \mu \mathrm{M}$ ) for $4 \mathrm{~h}$. Immunoprecipitation was achieved with the anti-phospho-Tyr15 antibody. Western blot detection of CDC2 and CDK2 present in the immunoprecipitates was then performed. (c) The 224-525 and the 224-525.C431S (catalytically inactive) mutants were transfected in HeLa cells, in the presence or absence of BN82685 (BN: $100 \mathrm{nM}$ ). CDK2 was immunoprecipitated from the corresponding fractions, and the Tyr15 phosphorylation was detected by western blot as in (a). (d) HeLa cells were transfected with wild-type (WT) or truncated (224-525) CDC25A. CDK2 was immunoprecipitated from these cells, and the co-immunoprecipitated forms of CDC25A were detected by western blot. CF: crude initial fraction. Western blot against CDK2 was used as a control. (e) U937 cells were treated for 5 or $15 \mathrm{~h} \mathrm{with} \mathrm{MG-132} \mathrm{(MG:} 5 \mu \mathrm{M}$ ), CDK2 was immunoprecipitated from the corresponding fractions, and western blotting against CDC25A was performed on these immunoprecipitates as well as the crude initial fractions (CFs). Western blotting against CDK2 was used as a control 
Altogether, these data suggest that in apoptotic cells, the p33-tCDC25A fragment is active and involved in CDK2 rather than in CDC2 regulation. We then transfected HeLa cells with the 224-525 CDC25A mutant, and tested the Tyr15 phosphorylation of CDK2 as described before. As shown in Figure 6c, overexpression of this truncation mutant decreased Tyr15 phosphorylation of CDK2. By contrast, ectopic expression of the catalytically inactive form of this truncation mutant (224-525.C431S) did not modify the Tyr15 phosphorylation status of CDK2. Importantly, this decrease of CDK2 phosphorylation was impaired by the presence of the pharmacological inhibitor of CDC25. We then tested the direct association of p33-tCDC25A with CDK2 (Figure 6d). Cells were transfected with wild-type CDC25A or with the 224-525 mutant, and immunoprecipitation of CDK2 was performed. Transfection of wtCDC25A generated a large amount of the full-length protein, and a much lower level of the $33-\mathrm{kDa}$ fragment, as detected in the crude fraction of these cells. Western blot analysis of the corresponding immunoprecipitate clearly indicates that the 33-kDa fragment more stably associates with CDK2 than full-size CDC25A. Transfection of the 224-525 mutant confirms the interaction of this form of the protein with CDK2. To confirm these data, cells were induced for apoptosis, and immunoprecipitation of CDK2 was performed, confirming the association with the endogenous p33-tCDC25A (Figure 6e). These data strongly suggest the existence of a stable complex between p33-tCDC25A and CDK2 in apoptotic conditions.

The C-terminal fragment of CDC25A can induce apoptosis. To estimate the function of the different forms of CDC25A in the apoptotic process, HeLa cells were transfected with WT and mutated versions of the phosphatase. The apoptotic process was followed by fluorescenceactivated cell sorting (FACS) analysis with Annexin V assay (Figure 7a) and by immunofluorescence microscopy

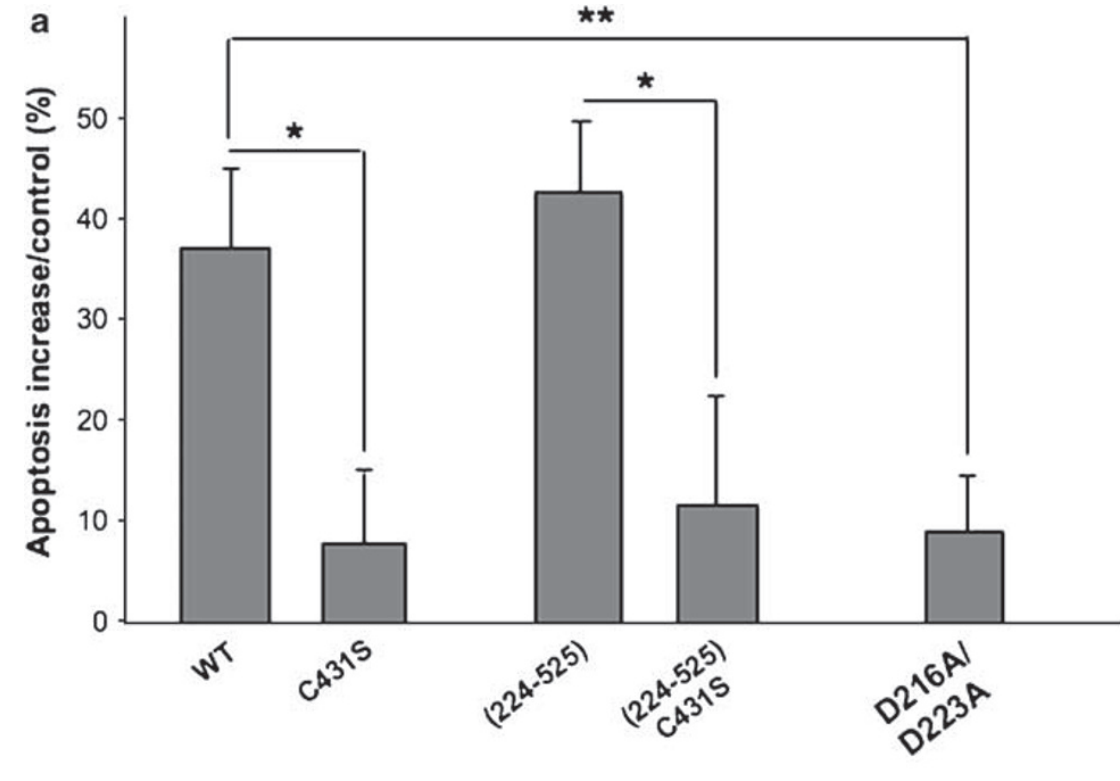

b

$\alpha$-act.Casp3

$\alpha-\operatorname{CDC25A}$

DAPI

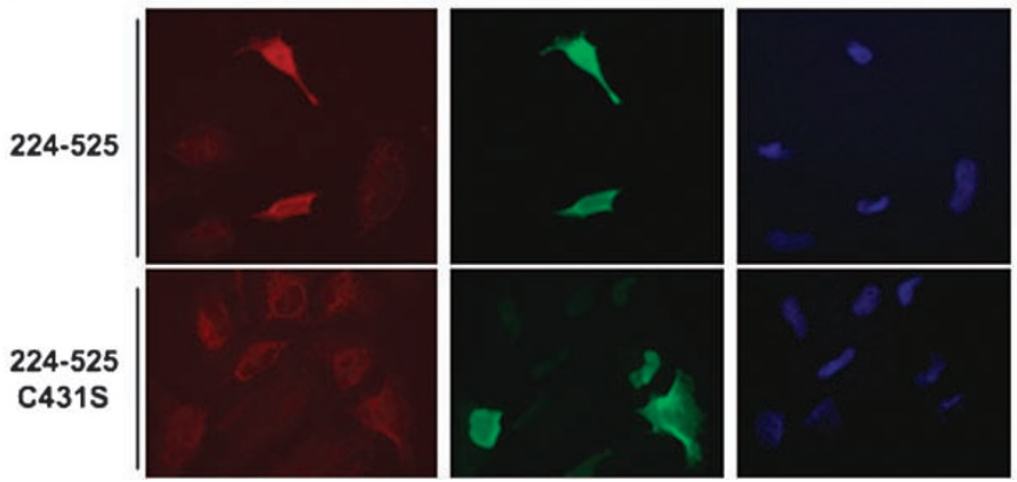

Figure 7 Truncated CDC25A induces apoptosis in HeLa cells. (a) HeLa cells were transfected with various CDC25A isoforms for $24 \mathrm{~h}$, and apoptotic cells were detected by Annexin V labeling and further FACS analysis. The wild-type (WT) protein, its inactive version (C431S), the short active form (224-525) and its inactive counterpart (224525).C431S as well as the caspase cleavage-resistant form (D216A/D223A) were used. The results are expressed as an increased percentage of apoptosis compared with control (transfection with the empty vector). ${ }^{*} P<0,05 ;{ }^{* *} P<0,01$. Data represent the mean \pm S.E.M. from four independent experiments. (b) HeLa cells were transfected with the 224-525 CDC25A mutant or its inactive form (224-525 C431S) and double immunostaining was performed with antibodies against CDC25A (green) and active caspase-3 (red). The transfected proteins are indicated on the left of the figure, and the antibodies used for the immunostaining are indicated on top of each panel 
following active caspase-3 immunostaining (Figure 7b). FACS analysis of Annexin $\mathrm{V}$ staining revealed that the WT and the 224-525 forms of CDC25A induced moderate apoptosis in their catalytically active versions, whereas their inactive mutants did not (Figure 7a). To establish whether WT CDC25A induced apoptosis due to its cleavage after transfection, we used the caspase cleavage-resistant mutant $\mathrm{D} 216 \mathrm{~A} / \mathrm{D} 223 \mathrm{~A}$. As expected, this mutant failed to induce apoptosis in HeLa cells, suggesting that a cleavage product of CDC25A is necessary for this purpose. Finally, overexpression of the 224-525 mutant induced caspase-3 activation in some of the cells where it was expressed (23\%) (Figure 7b), whereas the inactive form (224-525 C431S) did not (3\%). Altogether, these data demonstrate that truncated CDC25A can moderately initiate apoptosis by itself and that its phosphatase activity is necessary for this function.

\section{Discussion}

Cleavage of CDC25A during apoptosis. In this study, we demonstrate for the first time a caspase-dependent cleavage of the CDC25A phosphatase during apoptosis. This cleavage leads to reduced levels of full-size CDC25A and the accumulation of a $33-\mathrm{kDa}$ C-terminal fragment of this protein. Our findings strongly suggest that this cleavage is part of a maturation process rather than an initial step of degradation: first, this fragment persists in apoptotic cells when the full-size CDC25A has disappeared; second, p33-tCDC25A maintains a catalytic activity, in good agreement with a possible cellular function; third, we could not detect the N-terminal half of the protein by western blot, suggesting a different behavior of the two fragments; finally, the reinforced association with its target CDK2 is also in favor of a cellular function for this peptide.

CDC25A fragment localization and stability. One important consequence of this cleavage is that removing the $\mathrm{N}$ terminus of the protein implicates losing the NES while maintaining the nuclear localization domain, with subsequent relocalization of the protein. This was confirmed by our data that clearly indicate major nuclear localization of p33-tCDC25A. Our data also suggest proteasome-dependent regulation of $\mathrm{p33}-\mathrm{tCDC} 25 \mathrm{~A}$ levels. This may either be due to direct regulation of p33-tCDC25A by this system or to the regulation of the full-size protein influencing the cellular level of its cleavage product. The various described regulation sites in CDC25A involved in its proteasome-dependent degradation are localized in the $\mathrm{N}$-terminal part of the protein, which is missing in p33-tCDC25A (for a review, see Busino et $a .^{5}$ ). Our data argue in favor of a caspasedependent cleavage of the protein during non-genotoxic apoptosis while proteasomal degradation would occur following DNA damage. However, we do not rule out that both mechanisms are activated in the different apoptotic conditions, with one or the other being predominant and leading either to apoptosis or cell cycle arrest. An important issue emerging from this point is the status of the proteasome machinery in non-genotoxic apoptosis-induced cells. We used proteasome inhibitors as apoptosis inducers in hematopoietic cells, and this may of course affect the balance between CDC25A cleavage and its degradation by the proteasome. Furthermore, STS, in addition to being an apoptotic agent, is also known as a broad protein kinase inhibitor, and this may also affect this balance as protein phosphorylations are key events for protein ubiquitination process. Whether an additional and not yet described mechanism of degradation by the proteasome targeting the C-terminal domain of CDC25A exists and is specifically involved in p33-tCDC25A turnover remains to be established.

Cell cycle effectors as caspase targets. There are not many examples of such maturation process for cell cycle proteins, such as the CDK inhibitors p27 Kip1 and p21 Cip1, which have been characterized as caspase substrates. In some cases, a function was attributed to the cleavage fragment of these CKIs. ${ }^{15,16}$ Another interesting case of protein maturation through caspase cleavage concerns the pro-apoptotic protein Bid, which is myristoylated after cleavage by caspase- 8 and targeted to the mitochondria to induce apoptosis. ${ }^{17}$ More recently, cleavage of the cdc6 protein by caspase-3 was described, leading to the accumulation of a nuclear pro-apoptotic fragment of this protein. ${ }^{18,19}$ Interestingly, a major regulator of cdc6 is CDK2/ cyclinA: N-terminal phosphorylation of cdc6 by this complex induces its cytoplasmic translocation and inactivation. ${ }^{20}$ The cleavage of $\mathrm{p} 27^{\mathrm{Kip} 1}$ by caspase is of special interest when considering CDC25A, as the target of these two proteins is the same. The hypothesis that CDK2 activation during apoptosis is mediated by a caspase-dependent p27Kip1 inhibition and CDC25A activation would be interesting to validate. Furthermore, high $\mathrm{p} 27^{\mathrm{Kip} 1}$ levels have been described to protect cells against apoptosis in various systems.

Involvement of CDC25A in the apoptotic process. The involvement of CDC25A as positive or negative regulator of apoptosis remains controversial. ${ }^{9-11}$ By contrast, CDK2 activation during apoptosis has been reported in various systems, and was found necessary for the apoptotic process (see Guo and $\mathrm{Hay}^{21}$ for a review; Levkau et al. ${ }^{16}$ and Hakem et $a .^{22}$ ). This is consistent with our results, which suggest an activation of CDK2 occurring in apoptotic leukemic cells. Although we did not formally demonstrate it, the p33-tCDC25A peptide may be involved in this activation. Indeed, full-size CDC25A is almost totally downregulated in these cells, and the other members of the CDC25 family were not described as CDK2 regulators, although CDC25C was reported to induce S-phase entry in one study. ${ }^{23}$ Furthermore, the fact that ectopic expression of the truncation mutant reduced Tyr15 phosphorylation of CDK2 further reinforced this conclusion. Importantly, CDK2 activation was recently found necessary for Myc-induced apoptosis in murine and human fibroblasts. ${ }^{24}$ In good agreement with our findings, this was not the case when the authors induced apoptosis with etoposide instead of Myc overexpression. Although the molecular function of CDK2 in this context remains unclear, this appears to be of 
outstanding importance as CDC25A was also described as a transcriptional target of Myc and as a key effector of Mycinduced apoptosis. ${ }^{9}$

The major issue proposed by this study concerns the difference of function between full-size CDC25A and p33-tCDC25A. Indeed, our data clearly show that the full-size non-cleavable form of the phosphatase does not induce apoptosis, demonstrating that p33-tCDC25A, and not the fullsize protein, is the actual apoptotic inducer in our experiments. This implies an increased capacity of this truncated form to activate CDK2 in comparison to full-size CDC25A, or the specific regulation of a still unknown substrate of CDC25A by this fragment. There are converging arguments that can be deduced from our data to corroborate differential functions of the full-length and truncated forms. These are (i) the higher specific activity of the truncated form, (ii) the stable association seen between CDK2 and p33-tCDC25A, (iii) the highest capacity of the truncated form to dephosphorylate Tyr15 on CDK2, and (iv) the potential loss of regulation of catalytic activity due to the absence of the $\mathrm{N}$-terminal part of the protein. Altogether, these data describe a new molecular link between the deregulation of major components of the cell cycle and the apoptotic program.

\section{Materials and Methods}

Antibodies and pharmacological inhibitors. The proteasome inhibitors MG-132, lactacystine and epoxomycin were purchased from Calbiochem, as well as STS and the caspase inhibitors Z-VAD-FMK and Z-IETDFMK. Etoposide was from Sigma (St Louis, MO, USA) and TNF- $\alpha$ from Euromedex (France).

Monoclonal CDC25A, Chk1, E2F-1, and CDC2, and polyclonal CDC25A and CDK2 antibodies were from Santa Cruz (CA, USA). Polyclonal phosphoCDC2(Tyr15) and phospho-Chk1 antibodies were from Cell Signaling. Actin and $\beta$-tubulin monoclonal antibodies were from Sigma. Monoclonal anti-PARP and monoclonal anti-active Caspase-3 were from BD Pharmingen.

Cell lines and culture conditions. U937 and Jurkat cell lines were purchased from DSMZ (Germany), and grown in RPMI $+10 \%$ heat-inactivated fetal calf serum (FCS), in the presence of penicillin $(100 \mathrm{U} / \mathrm{ml})$-streptomycin $(100 \mu \mathrm{g} / \mathrm{ml})$ at $37^{\circ} \mathrm{C}$ and $5 \% \mathrm{CO}_{2}$. The human leukemic U937 cell line was stably transfected with pTarget or pTarget containing p35 cDNA in combination with a FLAG sequence as described earlier. ${ }^{25}$ These cells were kindly provided by Professor E Solary (Dijon, France). They were grown in suspension in RPMl 1640 medium containing $10 \%$ heat-inactivated FCS, and transfected cell populations were selected in the presence of $400 \mu \mathrm{g} / \mathrm{ml} \mathrm{G} 418$. HeLa cells (DSMZ) were maintained at $37^{\circ} \mathrm{C}$ and $5 \%$ $\mathrm{CO}_{2}$ as a monolayer culture in DMEM supplemented with $10 \%$ heat-inactivated FCS, $100 \mathrm{U} / \mathrm{ml}$ penicillin and $100 \mu \mathrm{g} / \mathrm{ml}$ streptomycin.

Annexin V apoptosis assay. Quantification of apoptotic cells was performed with Annexin V-FITC apoptosis detection kit I (BD Pharmingen) as described by the manufacturer.

Mutagenesis and transfections. Jurkat cells were transfected with expression vectors by the LipofectAMINE ${ }^{\mathrm{TM}}$ with Plus Reagent method (Invitrogen), and HeLa cells were transfected with Effectene (Qiagen) according to the manufacturer's instructions.

Converting the Asp216 and Asp223 residues into Ala in the cdc25A sequence was accomplished by altering the Asp codons GAT into the Ala codons GCT. The mutation was introduced by PCR with the forward primer (5'-CCACGGATCCATGG AACTGGGCCCGGAG-3'), the reverse primer ( $5^{\prime}$-CCGCTCGAGCGGTCAGAG CTTCTTCAGACG-3'), and mutagenic primers, the forward primer for D216A ( $5^{\prime}$-GATGAGGATGCTGGCTTCGTG-3') and the reverse primer (5'-CACGAAGCO AGCATCCTCATC-3'); for D223A, the forward primer (5'-GACCTTCTCGCTGGAG AGAAT- $\left.3^{\prime}\right)$ and the reverse primer ( $5^{\prime}$-ATTCTCTCCAGCGAGAAGGTC- $\left.3^{\prime}\right)$. For C431S mutants, the Cys codon TGC was mutated in Ser codon AGC with the forward primer ( $5^{\prime}$-GTGTTTCACAGCGAGTTTTC-3') and the reverse primer (5'-GAAAACTCGCTGTGAAACAC- $\left.{ }^{\prime}\right)$. For S82A/S88A mutant, the Ser82 codon TCA and the Ser88 codon TCT were mutated in Ala codon GCA and GCT, respectively, with the forward primer (5'-TCAACAGATGCAGGTTTCTGTCTAGA TGCTCCTGGGC-3') and the reverse primer (5'-GCCCAGGAGCATCTAGACAG AAACCTGCATCTGTTGA-3'). Cdc25A(224-525) truncated form was obtained by PCR, adding a START codon just before the Gly224. The products were cloned into pcDNA3 (Invitrogen). All mutants were verified by sequencing.

Western blot analysis and immunoprecipitation. In total, $2 \times 10^{6}$ cells were usually reduced in $75 \mu \mathrm{l}$ of Laemmli sample buffer, submitted to sonication, and boiled for $3 \mathrm{~min}$. Proteins were then resolved on SDS-PAGE and transferred to nitrocellulose membrane (Hybond-C Super; Amersham Pharmacia Biotech). Saturation of the membrane was performed for $1 \mathrm{~h}$ in Tris buffer saline with Tween $0.05 \%$ (TBS-T) containing $5 \%$ non-fat milk. Membranes were blotted with proper antibodies overnight at $4{ }^{\circ} \mathrm{C}$ or for $1 \mathrm{~h}$ at room temperature, washed three times with TBS-T, and incubated for $30 \mathrm{~min}$ with horseradish peroxidase-coupled secondary antibody (Cell Signaling). After three additional washes, detection was achieved by chemiluminescence (Supersignal; Pierce). For CDK2 and P-Tyr15 immunoprecipitation experiments, $5 \times 10^{6}$ cells were lysed in $1 \mathrm{ml}$ of the IP buffer (Tris $50 \mathrm{mM}$ (pH 8), NaCl $150 \mathrm{mM}$, EGTA $3 \mathrm{mM}, \mathrm{NP}-400.5 \%$, NaF $50 \mathrm{mM}, \mathrm{Na}$ orthovanadate $1 \mu \mathrm{M}, \beta$-glycerophosphate $10 \mu \mathrm{M}$, protease inhibitors (Boerhinger)) and kept for $20 \mathrm{~min}$ on ice. After centrifugation at 14000 r.p.m. for $10 \mathrm{~min}$ at $4^{\circ} \mathrm{C}$, the supernatant was incubated with $5 \mu \mathrm{g}$ of the anti-CDK2 antibody and $40 \mu \mathrm{l}$ of protein A-Sepharose $\mathrm{ON}$ at $4{ }^{\circ} \mathrm{C}$. Following two washes with the IP buffer, the immunoprecipitated material was resuspended in $60 \mu \mathrm{l}$ of Laemmli sample buffer, boiled for $3 \mathrm{~min}$ and analyzed by western blot with the anti-Tyr15-phosphorylated CDC2 antibody (Cell Signaling; 1:1000), which also recognizes the Tyr15-phosphorylated form of CDK2. For CDC25A and p35-tCDC25A immunoprecipitations, a similar protocol was used, except that the lysis buffer was brought to $450 \mathrm{mM}$ $\mathrm{NaCl}$ to better solubilize the p33-tCDC25A protein. Densitometric quantifications of the western blots were performed with the SyngeneTools software.

Coupled in vitro transcription/translation of CDC25A and in vitro cleavage assay. The in vitro transcription and translation of cDNAs encoding the human CDC25A WT and mutant protein were carried out with the TNT-coupled reticulocyte lysate system (Promega, Madison, WI, USA) according to the manufacturer's protocols. For in vitro cleavage by recombinant caspases, $2 \mu \mathrm{l}$ of crude reticulocyte lysate conditioned for CDC25A translation was incubated with $100 \mathrm{ng}$ of recombinant caspase-3 (BD Bioscience) and $40 \mu$ l of caspase assay buffer at $37^{\circ} \mathrm{C}$ for $1 \mathrm{~h}$. Cleavage products were resolved by $10 \%$ SDS-PAGE and visualized by western blotting.

In vitro CDC25A phosphatase activity. The activity of CDC25A was monitored using 3-O-methylfluorescein phosphate (OMFP) or FDP. The assay was performed in 96-well plates in a final volume of $200 \mu$ l. The immunoprecipitated proteins were diluted in assay buffer ( $30 \mathrm{mM}$ Tris- $\mathrm{HCl}(\mathrm{pH} 8.2), 75 \mathrm{mM} \mathrm{NaCl}, 1 \mathrm{mM}$ DTT, BSA $0.033 \%$, and $20 \%$ glycerol). The reaction was initiated by the addition of $25 \mu \mathrm{M}$ of OMFP. OMFP emission was measured with Fluoroscan (LabSystem; excitation filter: $485 \mathrm{~nm}$ and emission filter: $538 \mathrm{~nm}$ ). The MBP-CDC25B recombinant enzyme produced in bacteria was used as a positive control.

Preparation of nuclear and cytoplasmic fractions. In total, $4 \times 10^{6}$ cells were washed twice with PBS and pelleted by centrifugation at $1500 \times g$ for $5 \mathrm{~min}$. The pellet was resuspended in $400 \mu \mathrm{l}$ buffer A (10 mM HEPES pH 7.9, $1.5 \mathrm{mM} \mathrm{MgCl}_{2}, 10 \mathrm{mM} \mathrm{KCl}, 0.5 \mathrm{mM}$ DTT, $0.5 \mathrm{mM}$ PMSF, $10 \mathrm{mM} \mathrm{NaF}, 1 \mathrm{mM}$ $\mathrm{Na}_{3} \mathrm{VO}_{4}$, protease inhibitors) by gentle pipetting. The cells were allowed to swell on ice for $15 \mathrm{~min}$, after which $0.5 \%$ Igepal NP-40 was added. After vortexing, the homogenate was centrifugated for $30 \mathrm{~s}$ and the supernatant was kept as the cytoplasmic fraction. The nuclear pellet was resuspended in $50 \mu \mathrm{l}$ ice-cold buffer B (20 mM HEPES pH 7.9, $420 \mathrm{mM} \mathrm{NaCl}, 0.2 \mathrm{mM}$ EDTA, 25\% glycerol, $0.5 \mathrm{mM}$ DTT, $0.5 \mathrm{mM}$ PMSF, $10 \mathrm{mM} \mathrm{NaF}, 1 \mathrm{mM} \mathrm{Na}_{3} \mathrm{VO}_{4}$, protease inhibitors), incubated for $20 \mathrm{~min}$ and centrifuged for $2 \mathrm{~min}$ at $4{ }^{\circ} \mathrm{C}$. The supernatant was used as the nuclear soluble fraction.

Immunofluorescence. HeLa cells were grown on coverslips and transfected with various combinations of WT, D216A/D223A, and (224-525) CDC25A. After $24 \mathrm{~h}$, the slides were washed in PBS, fixed with $3.7 \%(\mathrm{w} / \mathrm{v})$ paraformaldehyde for $30 \mathrm{~min}$ and washed again in PBS. Cells were permeabilized by $0.2 \%(\mathrm{v} / \mathrm{v})$ Triton 
X-100 in PBS for 3 min and then incubated in 5\% FCS in PBS for 30 min. Primary antibodies were added for $1 \mathrm{~h}$. The polyclonal anti-cdc25 antibody (Santa Cruz) was used for these experiments. After several washes in PBS, secondary antibodies (anti-rabbit-Alexa Fluor 488 and anti-mouse-Alexa Fluor 594; Molecular Probes) were added. After washes in PBS, the coverslips were mounted with Vectashield ${ }^{\circledR}$ Hard Set Mounting Medium with $4^{\prime}-6^{\prime}$-diamidino-2-phenylindole (Vector Laboratories) and the preparations were observed by epifluorescence (Nikon Eclipse TE2000-U) microscopy.

Time-lapse video imaging. For mCFP-cdc25A-YFP cloning, cdc25A was amplified by PCR, adding $5^{\prime}-E C O R I$ and $3^{\prime}-B a m H I$ sites to the sequence. This CDNA was then inserted in-frame into the corresponding sites of the pCDNA3.1 mCerulean (mCFP)-Citrine (YFP) vector. Living cells were imaged on a heat DMI6000B Leica microscope (Leica Microsystems, Wetzlar, Germany) with a EL 6000 lamp. The microscope stage was covered with an incubation system, including a $\mathrm{CO}_{2}$ contoller and a temperature controller (Pecon). Images were acquired using the COOLsnapHQ2 charge-coupled device camera (Roper Scientific, Tucson, AZ, USA) and subsequently processed using MetaMorph (Universal Image, Downingtown, PA, USA) and Photoshop software packages. For visualizing realtime cleavage, all parameters were fixed, including the use of constant neutral density filtration to control intensity excitation, an integration time of $200 \mathrm{~ms}$ to optimize signal and minimize photobleaching, a $\times 40$ objective with a numerical aperture of 0.8 and a binning $2 \times 2$. Fluorescence images were monitored in two channels using DMl6000B filter wheel controlled by the metamorph image processing system with a CFP channel $(440 \pm 21 \mathrm{~nm}$ excitation, 455 DRLP, $480 \pm 30 \mathrm{~nm}$ emission) and YFP channel $(500 \pm 25 \mathrm{~nm}$ excitation, 525 DRLP, $545 \pm 35 \mathrm{~nm}$ emission). CFP and YFP were acquired sequentially and collected every $5 \mathrm{~min}$.

Acknowledgements. We are very grateful to Professor E Solary (Dijon, France) for providing us with the U937-p35 cell line. We also thank Fatima L'FaqihiOlive for expert assistance with the FACS experiments. This study was supported by the Institut National de la Santé et de la Recherche Médicale, by the Association Laurette Fugain (Grant no. R05027BB), by the Association pour la Recherche sur le Cancer (ARC, Grant no. 3638) by the 'Ligue Nationale contre le Cancer' (Equipe labellisée 2005 to BD) and by the Institut National du Cancer (INCA, Grant no. PL103).

1. Jinno S, Suto $\mathrm{K}$, Nagata A, Igarashi $\mathrm{M}$, Kanaoka $\mathrm{Y}$, Nojima $\mathrm{H}$ et al. Cdc25A is a novel phosphatase functioning early in the cell cycle. EMBO J 1994; 13: 1549-1556.

2. Blomberg I, Hoffmann I. Ectopic expression of cdc25A accelerates the G1/S transition and leads to premature activation of cyclin $\mathrm{E}$ - and cyclin A-dependent kinases. Mol Cell Biol 1999; 19: 6183-6194

3. Mailand N, Podtelejnikov AV, Groth A, Mann M, Bartek J, Lukas J. Regulation of G2/M events by $C D C 25 A$ through phosphorylation dependent modulation of its stability. EMBO J 2002; 21: 5911-5920.

4. Boutros R, Lobjois V, Ducommun B. CDC25 phosphatases in cancer cells: key players? Good targets? Nat Rev Cancer 2007; 7: 1-12.
5. Busino L, Chiesa M, Draetta GF, Donzelli M. CDC25A phosphatase: combinatoria phosphorylation, ubiquitylation and proteolysis. Oncogene 2004; 23: 2050-2056.

6. Chen X, Prywes R. Serum-induced expression of the CDC25A gene by relief of E2F mediated repression. Mol Cell Biol 1999; 19: 4695-4702.

7. Khaled AR, Bulavin DV, Kittipatarin C, Li WQ, Alvarez M, Kim K et al. Cytokine-driven cell cycling is mediated through CDC25A. J Cell Biol 2005; 169: 755-763.

8. Fernandez-Vidal A, Ysebaert L, Didier C, Betous R, De Toni F, Prade-Houdellier N et al. Cell adhesion regulates CDC25A expression and proliferation in acute myeloid leukemia. Cancer Res 2006; 66: 7128-7135.

9. Galaktionov K, Chen X, Beach D. CDC25A cell-cycle phosphatase as a target of cmyc. Nature 1996; 382: 511-517.

10. Fuhrmann G, Leisser C, Rosenberger G, Grusch M, Huettenbrenner S, Halama T et al. Cdc25A phosphatase suppresses apoptosis induced by serum deprivation. Oncogene 2001; 20: 4542-4553.

11. Zou X, Tsutsui T, Ray D, Blomquist JF, Ichijo H, Ucker DS et al. The cell cycle-regulatory CDC25A phosphatase inhibits apoptosis signal regulating kinase 1. Mol Cell Biol 2001; 21: 4818-4828.

12. Xue D, Horvitz HR. Inhibition of the Caenorhabditis elegans cell-death protease CED-3 by a CED-3 cleavage site in baculovirus p35 protein. Nature 1995; 377 : 248-251.

13. Xu G, Cirilli M, Huang Y, Rich RL, Myszka DG, Wu H. Covalent inhibition revealed by the crystal structure of the caspase-8/p35 complex. Nature 2001; 410: 494-497.

14. Kallstrom $\mathrm{H}$, Lindqvist A, Pospisil V, Lundgren $A$, Rosenthal CK. Cdc25A localisation and shuttling: characterisation of sequences mediating nuclear export and import. Exp Cell Res 2005; 303: 89-100.

15. Eymin B, Haugg M, Droin N, Sordet O, Dimanche-Boitrel MT, Solary E. Caspase-induced proteolysis of the cyclin-dependent kinase inhibitor p27Kip1 mediates its anti-apoptotic activity. Oncogene 1999; 18: 4839-4847.

16. Levkau B, Koyama H, Raines EW, Clurman BE, Herren B, Orth $\mathrm{K}$ et al. Cleavage of p21Cip1/Waf1 and p27Kip1 mediates apoptosis in endothelial cells through activation of Cdk2: role of a caspase cascade. Mol Cell 1998; 4: 553-563.

17. Zha J, Weiler S, Oh KJ, Wei MC, Korsmeyer SJ. Post-translational N-myristoylation of BID as a molecular switch for targeting mitochondria and apoptosis. Science 2000; 290 $1761-1765$

18. Yim H, Jin YH, Park BD, Choi HJ, Lee SK. Caspase-3-mediated cleavage of Cdc6 induces nuclear localization of p49-truncated Cdc6 and apoptosis. Mol Biol Cell 2003; 14: 4250-4259.

19. Yim H, Hwang IS, Choi JS, Chun KH, Jin YH, Ham YM et al. Cleavage of Cdc6 by caspase3 promotes ATM/ATR kinase-mediated apoptosis of HeLa cells. J Cell Biol 2006; 174 77-88.

20. Petersen B, Lukas J, Sorensen C, Bartek J, Helin K. Phosphorylation of mammalian cdc6 by cyclin A/CDK2 regulates its subcellular localization. EMBO J 1999; 18: 396-410.

21. Guo M, Hay BA. Cell proliferation and apoptosis. Curr Opin Cell Biol 1999; 11: 745-752.

22. Hakem A, Sasaki T, Kozieradzki I, Penninger J. The cyclin-dependent kinase 2 regulates thymocyte apoptosis. J Exp Med 1999; 189: 957-968.

23. Turowski P, Franckhauser C, Morris MC, Vaglio P, Fernandez A, Lamb NJ. Functional cdc25C dual-specificity phosphatase is required for S phase entry in human cells. Mol Biol Cell 2003; 14: 2984-2998.

24. Deb-Basu $D$, Aleem E, Kaldis $P$, Felsher DW. CDK2 is required by MYC to induce apoptosis. Cell Cycle 2006; 5: 1342-1347.

25. Cathelin S, Rebe C, Haddaoui L, Simioni N, Verdier F, Fontenay M et al. Identification of proteins cleaved downstream of caspase activation in monocytes undergoing macrophage differentiation. J Biol Chem 2006; 281: 17779-17788. 